\title{
Bioreducible Polycations as Shuttles for Therapeutic Nucleic Acid and Protein Transfection
}

\author{
Philipp M. Klein ${ }^{1,2}$ and Ernst Wagner ${ }^{1,2}$
}

\begin{abstract}
Significance: Nucleic acids such as gene-encoding DNAs, gene-silencing small interfering RNAs, or recombinant proteins addressing intracellular molecular targets present a major new therapeutic modality, provided efficient solutions for intracellular delivery can be found. The different physiological redox environments inside and outside the cell can be utilized for optimizing the involved transport processes. Recent Advances: Intracellular delivery of nucleic acids or proteins requires dynamic carriers that discriminate between different cellular locations. Bioreducible cationic polymers can package their therapeutic cargo stably in the extracellular environment, but sense the reducing intracellular cytosolic environment. Based on disulfide cleavage, carriers are degraded into biocompatible fragments and release the cargo in functional form. Disulfide linkages between oligocations, between the carrier and the cargo, or spatial caging of complexed cargo by disulfides have been pursued, with polymers or precise sequence-defined peptides and oligomers. Critical Issues: A quantitative knowledge of the bioreductive capacities within different biological compartments and the involved cellular reduction processes would be greatly helpful for improved carriers with disulfides cleaved within the right compartment at the right time. Future Directions: Novel designs of multifunctional nanocarriers will incorporate macromolecular disulfide entry mechanisms previously optimized by natural evolution of toxins and viruses. In addition to extracellular stabilization and intracellular disassembly, tuned disulfides will contribute to deshielding at the cell surface, or translocation from intracellular compartments to the cytosol. Antioxid. Redox Signal. 21, 804-817.
\end{abstract}

\section{Introduction}

$\mathbf{T}$ HE THERAPY WITH bio-derived macromolecules such as proteins or nucleic acids such as plasmid DNA (pDNA) (61), small interfering RNA (siRNA) (20, 113), and microRNA $(40,53)$ is a field of major importance and continually growing interest. Life-threatening, severe diseases, including cancer, obtain a new chance for treatment by the use of gene therapy $(6,10)$ or intracellular protein therapy $(30)$. In order to be used as therapeutics, these macromolecules should be stabilized against degradation in the bloodstream and clearance should be taken up by the target cells and reach the intracellular site of action.

Bacterial toxins developed sophisticated solutions for the transcellular and intracellular delivery of protein subunits. Viruses are the number one carriers for intracellular nucleic acid delivery. However, only minor changes in their structures can be made, the size and type of cargo is limited, and foreign proteins and viruses trigger immune reactions. Both such protein toxins and viral nanoparticles, on the one hand, present excellent natural examples for how to design carriers for intracellular delivery. On the other hand, synthetic carriers that mimic these transfer processes but are not dependent on naturally available nucleotides and amino acids gain more and more attention.

These synthetic carriers should handle a lot of challenging tasks. They should offer an optimal extracellular stability and an efficient uptake into the cell. Uptake usually results in delivery into endocytic vesicles, which often end in degradative lysosomes. Therefore, the same carriers should facilitate an escape from endosomes after uptake and release their nucleic acid or protein cargo to the cytoplasm, which is

\footnotetext{
${ }^{1}$ Pharmaceutical Biotechnology, Center for System-Based Drug Research, Ludwig-Maximilians-University, Munich, Germany.

${ }^{2}$ Center for Nanoscience (CeNS), Ludwig-Maximilians-University, Munich, Germany.
} 
optionally followed by transfer to the nucleus (as required in the case of pDNA). In this process, the carriers should act similar to shuttles: Although stably associated with their cargo in a covalent or noncovalent manner in the early extracellular delivery steps, they should not disturb the protein or nucleic acid cargo in functionality inside the cell and should dissociate or disintegrate after delivery.

Not only the demands on delivery differ at the different extracellular and intracellular sites, but also the microenvironments provide unique different properties. Carriers can be designed to sense these environmental differences and to utilize them to undergo changes that are beneficial for the delivery process (116). The molecular programming of such dynamic carriers may include sensors that react to changes in enzyme activities, $\mathrm{pH}$, or the redox microenvironment (Fig. 1). Among the different sensors, bioreducible elements are important tools that are used to distinguish between extraand intracellular sites, where the redox potential displays big differences. As reviewed in the next sections, the use of disulfide bonds as sensors for reductive environments have a growing impact in the development of oligocation-based macromolecular drug carriers $(48,91,104)$.

\section{Outside Stabile, Inside Labile-The Delivery Paradox}

Polyplexes are nanoscaled, interelectrolyte complexes consisting of cationic polymers and negatively charged nucleic acids (23). The extracellular stability is of highest importance. In the bloodstream, these particles are exposed to nucleases, which can degrade the cargo, and other serum proteins, which can destabilize the complex by electrostatic exchange actions. In addition, nucleic acids are compacted to convenient polyplex sizes of virus-like dimensions (around $100 \mathrm{~nm}$ ). In case of larger pDNA, this results in favorable compaction and protection. In case of small nucleic acids such as siRNA or oligonucleotides, this results in increased nanoparticle sizes due to packaging as multimers, which prevents the particles from being cleared too rapidly by the kidney (102). High-molecular-weight (HMW) polymeric carriers usually exhibit better transfection efficiency than do low-molecular-weight (LMW) carriers largely because of insufficient polyplex stability of the latter ones $(55,100,119$, 129, 130). LMW carriers, however, have significant advantages with regard to reduced cytotoxicity (124) and better biocompactibility; for example, a reduced complement activation (84) that is relevant for in vivo applications. Moreover, too tight binding by HMW polymers can hinder intracellular vector unpacking $(41,95)$ and, therefore, reduce transfection efficiency. pDNA should be accessible to the transcriptional machinery in the nucleus. siRNA should be accessible to the RNA-induced silencing complex (44), and the activity of therapeutic cargo proteins should not be affected by the carrier after delivery to the cytosol. Often, the window between sufficiently large polymer size for effectivity and sufficiently small polymer size for high biocompatibility was either small or nonexistent (7). To achieve a better carrier profile with stability on demand, strategies using biodegradable polymers have been explored. The concept often included bioreversible cross-linkage of nontoxic LMW oligomers into HMW carriers via hydrolysable ester, acetal bonds, or reducible disulfide bonds (4, 26, 31, 34, 49, 51, 79, 109). Thus, extracellular polyplex stability and transfection efficiency is partnered with intracellular disassembly and polymer degradation into nontoxic fragments.

Within physiological proteins, the presence of disulfide bonds dominates outside the cell, for secreted proteins, matrix proteins, or proteins at cell surfaces (21). Inside the cell, the combination of high glutathione (GSH) concentrations and enzymes from the thioredoxin family (39) forms a reductive environment of the cytosol. With a concentration of 1-11 $\mathrm{mM}$ GSH (94), the intracellular concentration of GSH is approximately 100-1000 times higher than outside the cell. This attribute can be also used by artificial reducible systems to be intracellularly cleaved and change their properties.

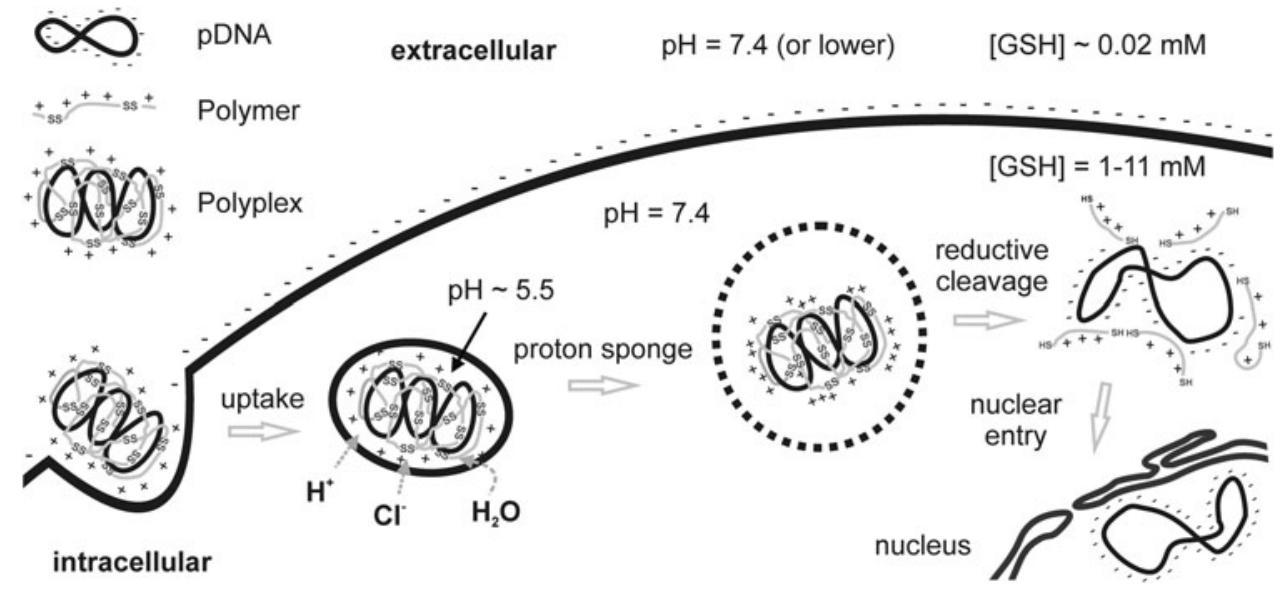

FIG. 1. Dynamic nanocarriers utilizing different cellular microenvironments. Differences in pH (lower in endocytic vesicles and also in special extracellular tumor situations) and redox situation (higher intracellular glutathione [GSH] concentration) can be utilized in the delivery process. Polyplexes stabilized by disulfide formation get internalized by an electrostatic interaction with the cell membrane. Protonation of polymers in the acidifying vesicle triggers destabilizing membrane interactions that are necessary to induce endosomal escape into the cytosol. In the reductive environment of the cytosol, disulfide bonds are cleaved and the cargo is released. Plasmid DNA (pDNA) has to enter the nucleus to get transcribed. 
Although extracellular stability is expected to be significantly improved by disulfides, the situation is not so clear-cut. Disulfide cleavages may also occur in the in vivo situation outside the cell (9). This was already observed in an early in vivo work using immunotoxins $(60,110)$. The liver as the major organ for GSH production $(15,127)$ has been considered as responsible for this extracellular degradation of disulfide bonds. Protein disulfide isomerases (PDI), widely known to be localized in the endoplasmatic reticulum (ER), can also occur on the cell surface of hepatocytes and may cleave disulfide bonds (77) Low concentrations of cysteine $(\sim 8 \mu M)$ and GSH $(\sim 2 \mu M)$ present in human plasma (43) are not considered to significantly contribute to extracellular bioreduction. The extracellular stability of disulfides can be tuned by their structural environment $(110,126)$; see also last section. Thus, appropriate redox chemistry is considered an excellent approach to solve the conflicting carrier requirements between extracellular stability and intracellular instability.

For example, in an early work, Rice and coworkers (68) introduced defined oligolysine structures containing one to five cysteine residues $\left(\boldsymbol{C W} \boldsymbol{K}_{\boldsymbol{1 8}}, \boldsymbol{I I}, \boldsymbol{I I I}, \boldsymbol{I} \boldsymbol{V}, \boldsymbol{V}-\right.$ Fig. 2). The oligomers became very reactive at $\mathrm{pH} 7.5$; for example, oligomer $\boldsymbol{V}$ oxidized completely within $25 \mathrm{~min}$. For this reason, the mercapto forms of oligomers were stored at low $\mathrm{pH}$ in the absence of oxygen until use. During the incubation with pDNA at physiological $\mathrm{pH}$, the cysteines formed disulfide bonds. Polyplexes of oligolysines with more than three cysteines, which were able to cross-link in three dimensions,

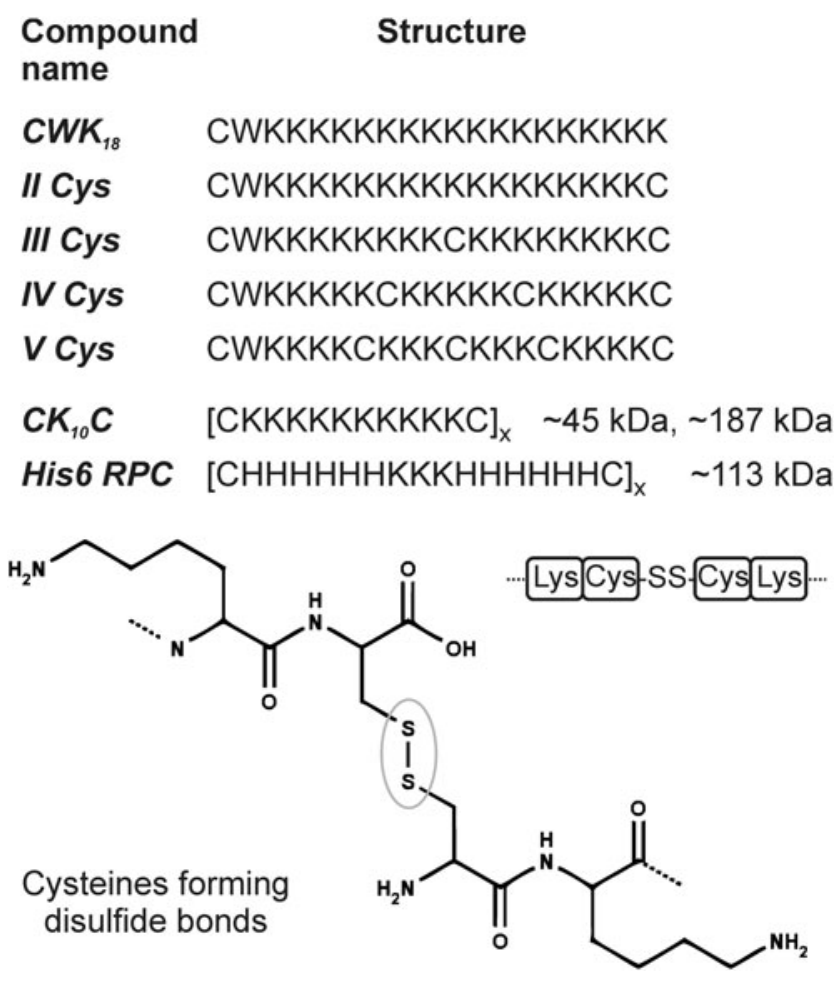

FIG. 2. Polymers based on natural amino acids with cysteine for linking. Structures of oligomers (sequences from $\mathrm{N} \rightarrow$ C-terminus) that are able to form bioreducible linkages by dimerization [CWK18 (68)], in a linear [II Cys (68), CK10C (87), His 6 (88)], or cross-linking [III-V Cys (68)] way. C, cysteine; $\mathrm{W}$, tryptophane; $\mathrm{K}$, lysine; $\mathrm{H}$, histidine. exhibited the best stability in a shear stress stability test and could outperform polylysine tremendously. Still, the structure with two cysteines that has only the possibility to polymerize in a linear way revealed the best results in transfection with stability properties which are comparable to polylysine polyplexes. The stability of the resulting particles was higher if the thiols of the cysteines were kept in the reduced form until they were incubated with the DNA. It seems that these bioreducible oligocations created a cage after complexing with the DNA template. This outcome was very promising, especially when considering that these oligolysine structures were not expected to have high transfection efficiency. Endosomal buffer capacity and endosomal escape activity of polylysines was known to be very modest. Based on analogous preoxidized polymers, containing Cys-Lys ${ }_{10}-\mathrm{Cys}$ monomers ( $\boldsymbol{C} \boldsymbol{K}_{10} \boldsymbol{C}-$ Fig. 2), lipopolyplexes were generated (87) by a combination with a liposomal transfection agent for enhanced endosomal escape. This lipopolyplex system achieved 187-fold higher gene expression levels for pDNA compared with the analogous nonreducible lipopolylysine formulation. The effect of reducing agents for these polymers was demonstrated by adding $25 \mathrm{~m} M$ dithiothreitol (DTT) for 5 min to polyplexes in an ethidium bromide pDNA binding assay. In this assay, the pDNA polyplexes with nonreducible polylysine exhibited no significant changes. The pDNA polyplexes with reducible polymers, however, showed a more than twice higher fluorescence intensity than before the addition of DTT. The higher fluorescence intensity represents better accessibility of the DNA to the intercalator ethidium bromide. Importantly, in more general terms, the better accessibility based on bioreductive carrier cleavage improves pDNA delivery by facilitating the release of the nucleic acid in a form that is accessible for transcription into mRNA.

\section{Bioreducible pDNA Carriers with Endosomal Escape Function}

For successful gene transfer, several delivery barriers should be overcome (see Fig. 1). Release from endosomes after cellular uptake presents a major bottleneck. Polyethylenimine (PEI), a polymer often used for pDNA transfections, combines optimized DNA binding ability and endosomal buffer capacity within one structure $(3,131)$. Its diaminoethane motif (108) offers a remarkable $\mathrm{pH}$-reversible protonation and buffer capacity over a wide $\mathrm{pH}$ range, which turns it into an almost perfect "proton sponge" (1, 2, 105, 115). Endosomal protonation of PEI was discovered as an excellent way for triggering lipid membrane disruption and release into the cytosol. In sum, PEI has been established as being a very effective as well as a significantly cytotoxic (32, 74) gene carrier. In order to create a less toxic, bioreducible branched PEI, LMW (<4.6 kDa) linear PEI (LPEI) was cross-linked with dithiodipropionic acid di(N-succinimidyl ester) (DSP) or N,N'-bis-(tert-butoxycarbonyl)cystine linkages (Fig. 3) (4). Impressively, this bioreducible PEI version did not only display far lower cytotoxicity at higher PEI doses, but also significantly outperformed the transfection efficiency of standard branched PEI $25 \mathrm{kDa}, \boldsymbol{L P E I} 22 \mathrm{kDa}$, and several other commercially available reagents in seven cell lines (CHO-K1, COS-7, NIH/3T3, HepG2, HCT116, HeLa, and HEK-293 cells). For the maximum efficiency for these bioreducible polymers, N/P ratios (ratio between 
FIG. 3. Structures of PEI and bioreducible polymers. Nondegradable linear $\boldsymbol{L P E I}$ and branched $\boldsymbol{B P E I}$ (left top). Bioreducible $\boldsymbol{b P E I}$ derivates (LRx-lPEIy and BCx-lPEIy) (4) based on $\boldsymbol{L P E I}$ and crosslinker ( $\mathrm{x}$ denotes the molar ratio cross-linker/LPEI, and y denotes the MW (kDa) of the LPEI. For LRx-IPEIy, the molar ratio between linker and $\boldsymbol{L P E I}$ monomers was 0.5\%-3\%; for BCX-lPEIy, the molar ratio between linker and $\boldsymbol{L P E I}$ monomers was 3\%-8\%). bPEIS (52) contains a bioreducible diaminoethane system and a nondegradable cross-linker. SS-PAEI (12, $63,64)$ consists of poly(amido ethylenimine) with bioreducible disulfide bonds and variable residues for functionalization (right bottom).

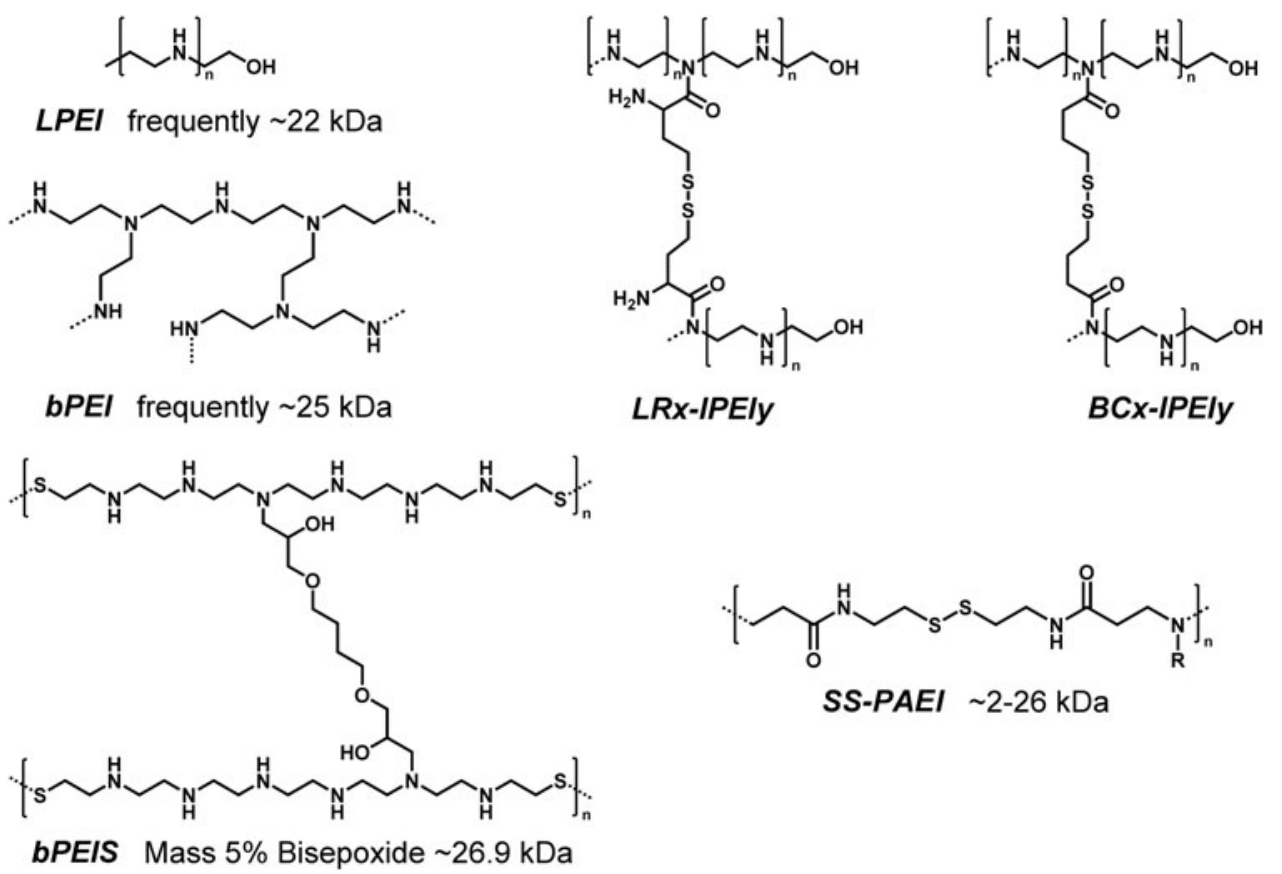

bPEIS Mass $5 \%$ Bisepoxide $\sim 26.9 \mathrm{kDa}$ protonable nitrogens in polymer and phosphates in nucleic acid) between 18 and 30 were required, which were much higher than for nonbioreducible polymers.

A related effort to produce a biodegradable PEI was taken by Park and coworkers (52). They synthesized a bioreducible linear PEI with a diaminoethane motif that was separated by a disulfide bond after every six protonatable amines (PEIS). An agarose gel shift showed a less than $2 \mathrm{~h}$ stability in a $5 \mathrm{mM}$ GSH solution. As an additional development, these linear bioreducible PEIS were cross-linked to larger structures with different amounts of bisepoxide. This resulted in branched structures (bPEIS - Fig. 3) with increased stability of more than $4 \mathrm{~h}$ in GSH-containing buffer. The transfection for the larger branched PEIS was better than for the smaller linear $\boldsymbol{P E I S}$ and could reach the same level as branched PEI $25 \mathrm{kDa}$ at their own optimal N/P ratio. The addition of $5 \%$ bisepoxide showed best effects in general (results of five cell linesC2C12, HEK 293, HeLa, HUVEC, and NIH3T3). By adding $10 \%$ serum, the transfection of bioreducible PEIS was reduced by approximately one log scale, which was more than for $\boldsymbol{b P E I}$ (approximately half a log scale). Due to the bioreducibility and the small, calculable degradation products, the cell viability tested with MTT assay was significantly improved. On the other hand, serum stability was an issue that still needed improvement.

Disulfide containing poly(amido ethylenimine)s (SSPAEIs - Fig. 3) are another class of bioreducible polymers $(12,63,64)$. To form branched structures, agents containing at least two reactive amines such as ethylenediamine (EDA), diethylenetriamine (DETA), or triethylenetetramine (TETA) (12) were reacted by a Michael-type polyaddition with disulfide-containing bisacrylamides. The resulting polymers exhibit very good transfection results. Especially in $10 \%$ serum, they have great advantages compared with branched PEI $25 \mathrm{kDa}$. SS-PAEIs only had slightly lower transfection efficiency in serum $(1.2 \times$ difference for EDA polymers, $1.3 \times$ difference for DETA polymers, and $11 \times$ difference for TETA polymers) in BAEC cells, whereas $\boldsymbol{b P E I}$ had a dramatic loss with $500 \times$ difference compared with the serum-free group. SS-PAEIs also offer another topology; comb-like structures can be achieved by introducing side chains into the bioreducible backbone (64). In addition, a variety of functional elements can be incorporated with these side chains. These elements can be tertiary amines for nucleic acid binding, imidazoles for endosomal buffering, or protected secondary amines such as diaminoethane structures or spermine (63), which can be unprotected after the polyaddition. Besides these cationic structures, other functional groups such as hydrophobic elements can be introduced (64). Polymers resulting from such reactions do not have a precise structure, but due to their bioreducibility the cleavage products are small. These bioreducible poly(amido amine)s as well as related polyaspartamide-based disulfide-containing brushed PEI derivatives (128) exhibited lower cytotoxicity and often more efficient gene delivery than branched PEI $25 \mathrm{kDa}$.

A modification that strongly improved the efficacy of polylysine and oligolysine shuttles was the introduction of histidines $(73,81,88)$. The second imidazole nitrogen exhibits ideal basicity (pKa 6.0) for an increase of endosomal buffer capacity (lower protonation at physiological than at more acidic endosomal $\mathrm{pH}$ ), thereby facilitating endosomal release by the "proton sponge effect" that was previously hypothesized for PEI. Thus, it was possible to mediate efficient delivery not only for pDNA but also for mRNA and much smaller siRNA (more information on siRNA delivery in the next section) with one single vector (88). A histidine/ lysine ratio of 4:1 in a $\mathrm{Cys}_{-} \mathrm{His}_{6}-\mathrm{Lys}_{3}-\mathrm{His}_{6}$-Cys monomer (His6 RPC - Fig. 2) provided the best results.

\section{Design of Precise Oligomers for pDNA Transfection}

To combine the beneficial transfection properties of bioreducible PEI and related oligoethyleneimine polymers with a 
precise chemical structure, solid-phase-supported polymer synthesis (35-38) was introduced. In particular, artificial amino acids containing short defined repeats of the diaminoethane motif were prepared in boc/fmoc protected form, which was appropriate for standard automated or manual peptide synthesis (96). These building blocks, optionally in combination with natural amino acids such as cysteine and other units, were incorporated into peptide-like oligomers. The artificial amino acids provide the oligomers with proton sponge capacity. For example, Stp (succinoyl tetraethylene pentamine) within a polyamide chain provides three protonatable amines, and the building block Sph (succinoyl pentaethylene hexamine) provides four protonatable amines (Fig. 4). By solid-phase synthesis technologies, such defined oligomers can be generated with high precision in libraries of various sequences and defined lengths. Initial screenings of such a small library based on the Stp building block were performed for pDNA transfer activity (98). Compared with standard polymers, the oligomers present LMW carriers. Consistent with their incomplete protonation at physiological $\mathrm{pH}$, oligomers did not display significant cytotoxicity and were well biocompatible. Not unexpectedly, their limited

23

51

74

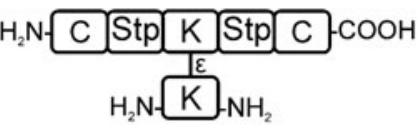

78

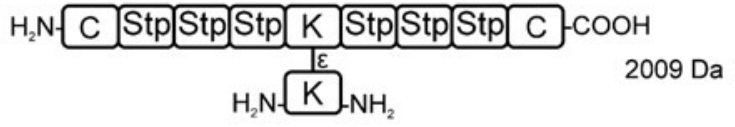

82


FIG. 4. pDNA carrier polymers based on artificial amino acids. There is no gene transfer activity for small structures without cysteines such as compound 23 (98). Structures $\mathbf{5 1 , 7 4 , 7 8 , 8 2}$ with two cysteines (98) for linear linking profit from longer cationic binding regions. 519 (92) presents cross-linking ability in a four-arm structure with a longer diaminoethane motif (Sph). size also provides limited polyplex stability. Compound 23 (Fig. 4) with 5 Stp units (representing 15 protonatable nitrogens) provided only very low polyplex stability in agarose gel electrophoresis assays and had no transfection efficiency at all. The incorporation of two cysteines, which after pDNA complexation form disulfide bonds by air oxidation, strongly improves polyplex stability and gene transfer activity. Compound 74 with two cysteines and only two Stps did not transfect, compound 51 with 3 Stps showed low but significant gene transfer for N/Ps $>6$, and compounds 78 and 82 with 6 or 8 Stp units and the two terminal cysteines revealed much better transfection results for N/Ps $\geq 15$ (98). These results indicate that even for oligocations which are able to interact with each other by disulfides a certain minimum of cationic binding units in each oligomer is required for activity. An additional measure for optimizing these LMW carriers was the attachment of hydrophobic fatty acids. These have stabilizing effects and mediate $\mathrm{pH}$-dependent endosomolytic activity. In an optimized form, such carriers outperformed the gold standard $\boldsymbol{L P E I} 22 \mathrm{kDa}$ (98).

Standard LPEI $22 \mathrm{kDa}$ contains approximately 500 protonatable nitrogens. Synthesis of such large linear structures by solid-phase-assisted synthesis is not feasible. An approach to circumvent this limitation of length was the design of fourarm structures. These structures contain two consecutive lysines as branching points via both alpha- and epsilon amine modification followed by simultaneous elongation of each arm with two to five units of Stp, Sph, or other artificial amino acids. Optionally terminal cysteines were integrated (92). By this procedure, in a few coupling steps, easily carriers with approximately more than hundred nitrogens (approximately 68 protonatable nitrogens) were generated.

Screening for pDNA transfection showed the following: The number of nitrogens per building block (Sph containing $6 \mathrm{~N}>$ Stp with $5 \mathrm{~N}>\mathrm{Gtt}$ with $4 \mathrm{~N}$ ) was more important for pDNA polyplex condensation and transfection than the total number of nitrogens per oligomer. Sph-based four-arm structures with three repeating units per $\operatorname{arm}\left(\mathrm{Sph}_{3}, 72\right.$ ethylenimine nitrogens in total) displayed comparable transfection activity as $\boldsymbol{L P E I}$ already in the absence of cysteines, whereas Gtt-based four arms with four repeating units $\left(\mathrm{Gtt}_{4}, 64\right.$ ethylenimine nitrogens in total) were inactive. In all cases, the presence of terminal cysteines further enhanced transfection activity (92). Apparently, this bioreversible option for disulfide-based stabilization was beneficial. The transfection activity of the most potent cysteine-containing Sph four-arm compound 519 (Fig. 4) exceeded the gold standard $\boldsymbol{L P E I}$ by approximately 50 -fold for the N/P ratio 12 .

\section{Cargo Matters: Reversible Disulfide Bonds Stabilizing siRNA Polyplexes}

The delivery of siRNA with cationic systems poses different challenges than pDNA $(57,102,118)$. Although both nucleic acids contain a negatively charged backbone (phosphodiester for physiological or phosphorothioate in case of some stabilized nucleid acids), the number of base pairs (bp) per molecule and their topology are different. With a $7 \mathrm{~nm}$ rod-shaped size, 21-23 bp, and 42-46 anionic charges per molecule $(16,117)$, siRNA is comparatively small and cannot offer thousands of negative charges that a long cyclic pDNA provides for binding. This results in a lower electrostatic 
stabilization, less gain in entropy by complex formation, and, therefore, less stable siRNA polyplexes. Most of the previously described systems for the transport of pDNA, including polylysine (71) and PEI (57), show much less efficiency in siRNA transfection unless appropriate modifications are introduced. One of the encouraging options presents the incorporation of bioreducible stabilizing disulfide bonds, by the cross-linking of siRNA into more "DNA-like" oligomers $(58,75)$, by linking siRNA with the cationic carrier $(19,70$, 80 ), or by cross-linking the cationic carrier molecules.

Based on the knowledge of pDNA delivery systems, new carriers have been invented to accomplish the delivery of siRNA. The approximately $4 \mathrm{kDa}$ pseudodendritic degradable oligomer $\boldsymbol{H D O}$, consisting of $800 \mathrm{Da}$ oligoethylenimine and 1,6-hexandiol diacrylate, was evaluated for siRNA delivery (29). This LMW polymer had previously been proved as an effective pDNA carrier (89), but it did not mediate siRNA delivery. Modification of siRNA/HDO polyplexes with DSP provided bioreversible stabilization (Fig. 5, top), as demonstrated by improved siRNA binding ability in an agarose gel electrophoresis assay. The change in the structures of polyplexes could be monitored by the measurement of size and zeta potential. For example, the size of particles formed at $\mathrm{N} / P 4$ increased from $113 \pm 3 \mathrm{~nm}$ to $197 \pm 3 \mathrm{~nm}$, and the zeta potential decreased from $27.6 \pm 0.4 \mathrm{mV}$ to $20.1 \pm 0.7 \mathrm{mV}$. Only the disulfide-stabilized siRNA/HDO polyplexes were taken up by cells and resulted in efficient gene silencing.

The importance of disulfide-based cross-linking for siRNA can be observed when using precise sequence-defined oligomers that are built by solid-phase synthesis as described earlier. Three-arm structures such as $\mathbf{3 8 6}$ (Fig. 5) $(28,97)$ that contain Stp units for nucleic acid complexation were able to bind and transfect siRNA only when containing cysteines for cross-linking at the end of each arm. The structure $\mathbf{3 8 6}$ showed perfect binding in electrophoresis gel shifts for low N/P ratios from 3 onward, whereas control structure 387 was inactive. Analogously, four-arm structures (92), which can transfect pDNA even without cysteine incorporations, were inactive for siRNA delivery. Cysteines at the end of each arm (519- Fig. 4) resulted in enhanced transfection efficiency for pDNA and were absolutely required for siRNA-based gene silencing.

T-shaped lipooligomers such as 49 (Fig. 5) were also dependent on the two stabilizing cysteines. Both the alanine analog (216) and compound 49 reacted with $\mathrm{N}$-ethylmaleimide, irreversibly blocked the thiol groups against disulfide-based stabilization, and lost the gene silencing activity (28). FCS measurements in $90 \%$ serum revealed that the size of 49 polyplexes for $\mathrm{N} / P 12$ increased from $49 \mathrm{~nm}$ within $30 \mathrm{~min}$ to $68 \mathrm{~nm}$ at room temperature. At $37^{\circ} \mathrm{C}$, the polyplex was stable after $10 \mathrm{~min}$, but some dissociation was already observed after $30 \mathrm{~min}$ (111). Disulfide stabilization was also required for gene silencing using the lipooligomer $\mathbf{E H C O}$ (Fig. 5). (122). This solid-phase synthesis-derived siRNA carrier contains $\mathrm{pH}$-sensitive EDA and histidine units, stabilizing cysteine and oleic acid units.

In order to improve polylysine properties, Kataoka and coworkers used a polyethylene glycol (PEG) -polylysine block polymer, which was reacted with iminothiolane (67). Next, a few thiols were incorporated onto lysines without losing cationic charges, because the primary amines are converted into positively charged amidines. With siRNA, so-called polyion complex (PIC) micelles are formed. The presence of the iminothiolane modification results in disulfide-based cross-linked polymers stabilizing the siRNA containing PIC micelles. These micelles were able to achieve 100-fold higher transfection efficiencies than the analogous micelle without cross-linking. Stability tests with increasing concentrations of sodium chloride revealed that the stability of cross-linked polyplexes was significantly increased and could be abolished with reducing agents. Polyplexes with unmodified PEGylated polylysine were not even stable at a physiological ionic strength.

Many multifunctional carriers for siRNA that are based on the same principle but including shielding and targeting
FIG. 5. Carriers optimized for siRNA delivery. dithiodipropionic acid di $(\mathrm{N}-$ succinimidyl ester) (DSP) linked with free amines on the surface of $\boldsymbol{H D O} / \mathrm{siRNA}$ polyplex (29). Active threearm structure $\mathbf{3 8 6}$ and its inactive analogue $\mathbf{3 8 7}(28,97)$. Lipooligomer EHCO (122) with histidine, cysteine, and oleic acid (OleA). Active t-shaped polymer 49 and its inactive analogue 216 (28).

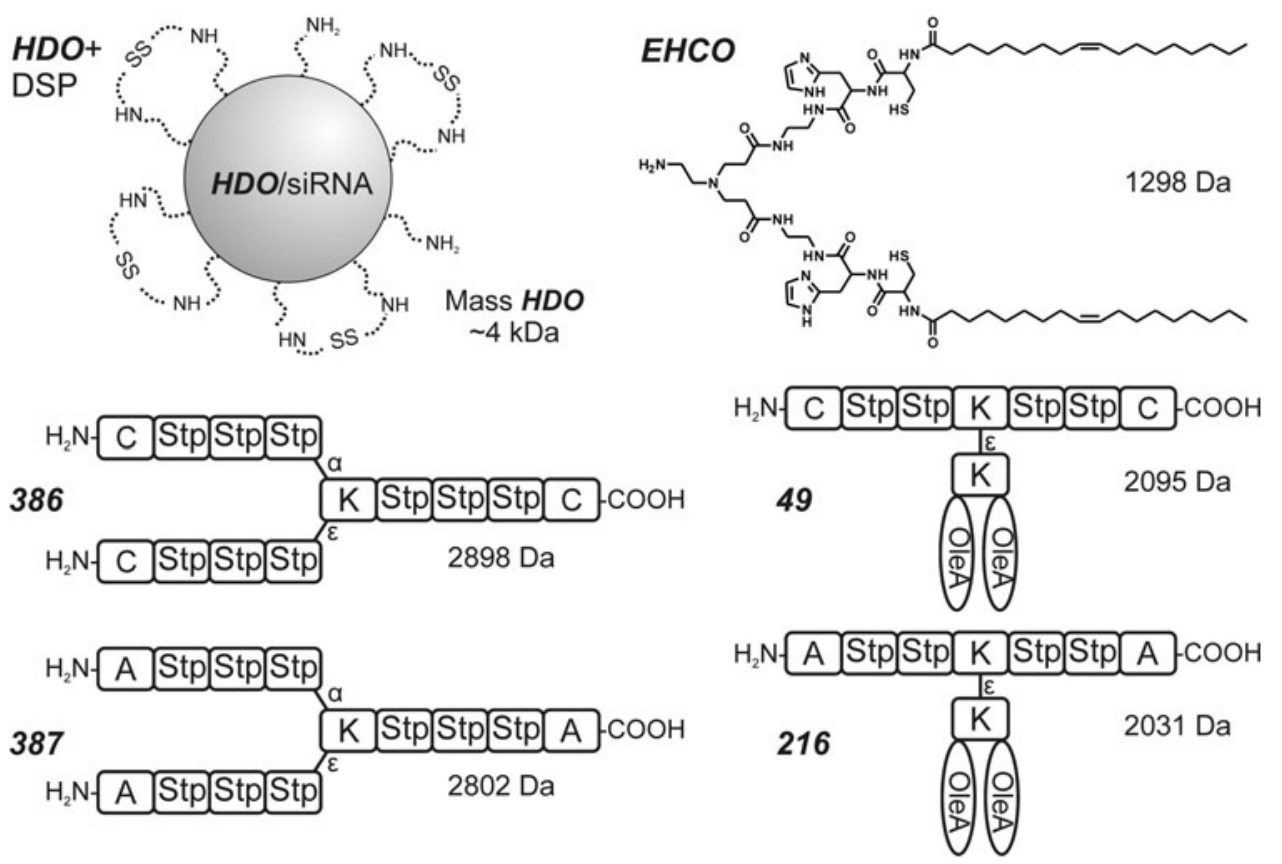




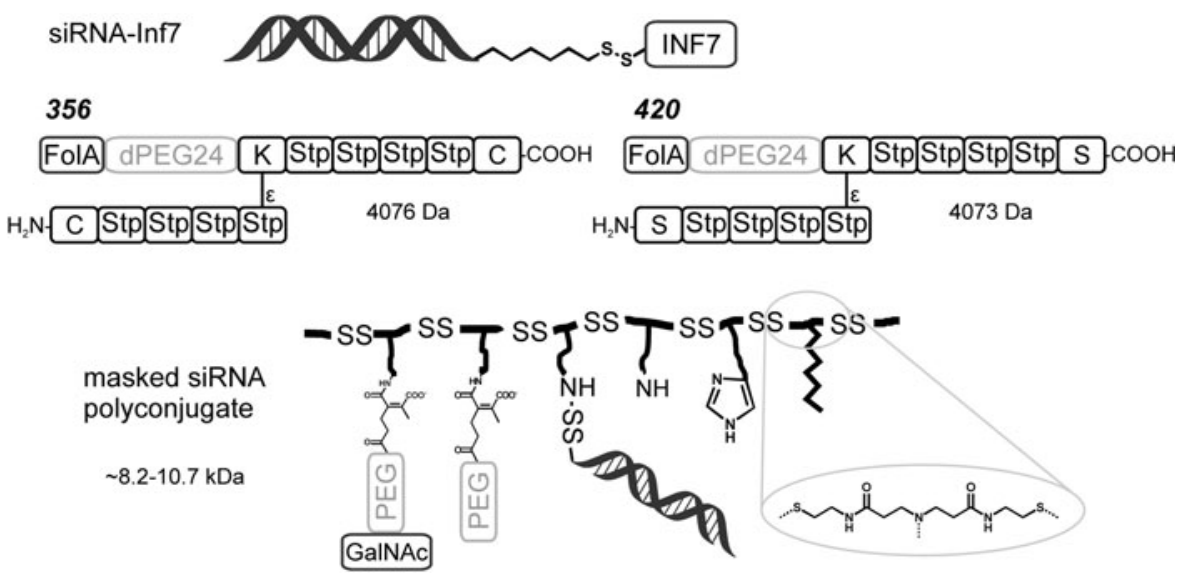

FIG. 6. Multifunctional siRNA polyplexes containing $\mathrm{pH}-$ and redox-sensitive components. Active 356 forms an efficient carrier with siRNA-INF7, whereas control 420 with serine instead of cysteine shows low binding and transfection efficiency (18). The masked siRNA polyconjugate presents a shuttle with pH-reversible PEGylation with and without targeting ligand, covalently bound siRNA, imidazole residues, and fatty acids based on a bioreducible poly(amido amine) backbone (80). domains also rely on disulfide bonds (18). For example, the folate receptor-targeted oligomer 356 (Fig. 6) formed stable nanosized siRNA complexes of only $6 \mathrm{~nm}$ hydrodynamic diameter. Replacing cysteines by serines (compound 420) resulted in a dramatic loss of siRNA binding as well as gene silencing activity. An additional use of bioreducible disulfides in this polyplex was the reversible covalent linkage of the siRNA with an endosomolytic influenza virus-derived peptide INF7 (Fig. 6), which was important for an efficient endosomal escape and cytosolic delivery.

This reversible linking can also be used for attaching siRNA directly to a carrier. Using click chemistry, a PEG folate was covalently attached to siRNA via a disulfidecontaining linkage (19). In addition, polycations were attached in this manner. Disulfides have been used to connect siRNA covalently to a pH-responsive masked endosomolytic polylysine carrier (70). Wang and coworkers used it for coupling to a bioreducible poly(amido amine) backbone (Fig. 6 , bottom) (80). The side chains of the backbone in this carrier were functionalized with hydrophobic modifications, imidazoles, and pH-reversible targeting ligands. These multifunctional systems with bioreducible properties demonstrated efficient, targeted gene silencing in vivo. The best performing polymer with a mixture of 40/30/30 molar ratio of 2-(2-aminoethoxy)ethyl/2-(1H-imidazol-4-yl)ethyl/dodecyl and a molar weight of $\sim 8.64 \mathrm{kDa}$ showed $80 \%$ mRNA knockdown in mice.

\section{Protein Delivery by Covalently Linked Bioreducible Shuttles}

Recombinant proteins present an important and growing class of modern biotherapeutics. Many of them, such as monoclonal antibodies or recombinant growth factors, have targets on extracellular sites $(106,114)$. Other proteins contained as antigens within vaccines are internalized into phagocytic cells and are degraded into peptides during the immune response. An efficient technology for intracellular cytosolic delivery of intact proteins ("protein transduction") would tremendously open the applicability of a new class of therapeutic proteins and antibody domains that aim at intracellular molecular targets.

Natural proteins teach us that intracellular protein transduction can be feasible. The human immunodeficiency virus 1 (HIV-1), trans-activator of transcription (TAT) protein $(27$,
33 , or the Antennapedia homeobox protein can cross cytoplasm membranes and internalize into cells under physiological conditions (42). A series of bacterial cytotoxins internalize by endocytosis, followed by subsequent translocation of a cytotoxin subunit across the endosomal membrane. In some cases, the reduction of disulfide bonds facilitates this delivery process. Such reduction-activated cytotoxins have been utilized in drug delivery; for example, listeriolysin-SS-oligocation conjugates for pDNA delivery $(11,90)$ or numerous immunotoxins $(24,25,101)$. Commonly used synthetic protein delivery systems include cationic lipids $(13,14,62)$, protein transduction domains $(45)$, such as natural penetratin $(85,93)$ and HIV-TAT $(45,103)$, or artificial oligoarginines (93) and cationic polymers $(17,30,59)$.

The sequence-defined oligocationic carrier $\mathbf{3 8 6}$ described in the previous section can also be applied for protein delivery (Fig. 7) (65). This disulfide-conjugated carrier delivers its protein cargos by endocytosis and accomplishes the escape from the endosome via "proton sponge effect,"-facilitating diaminoethane motifs. The carrier showed a 20 times more efficient cellular internalization of a nuclear localization sequence (nls)-tagged enhanced green fluorescent protein (EGFP) peptide than TAT peptide-mediated delivery of tatnls-GFP. Importantly, the carrier should not impair the function of the therapeutic protein. The bioreducible bond between the carrier and nlsEGFP was critical for nuclear localization. Analogous conjugates with irreversible thioether linkages were internalized into cells but remained entrapped in cytosolic structures and not transferred into the nucleus (66).

\section{Tuning the Timing and Extent of Bioreduction of Dynamic Carriers}

The various approaches for dynamic stabilization of bioconjugates and nanoparticulate carriers reviewed in the earlier sections build on the favorable difference between extracellular/intracellular redox conditions and GSH concentration. However, the frequently claimed notions that a) "disulfide bonds are generally stable outside the cell" or b) that "they are easily cleaved in endosomes" should be questioned as already stated earlier in literature (22), and might be even, in part, misconceptions, or, at least, not generally valid.

Several disulfide-bonded protein conjugates and immunotoxins have been found to be cleaved in vivo after 
FIG. 7. Protein transduction with cationic carrier. Green fluorescent protein (nlsEGFP) covalently modified with the three-arm carrier 386 via disulfide bonds (65) displays an enhanced uptake, escapes the endosome by the "proton sponge effect," and after cleavage from the carrier, enters the nucleus via the incorporated nls peptide sequence.

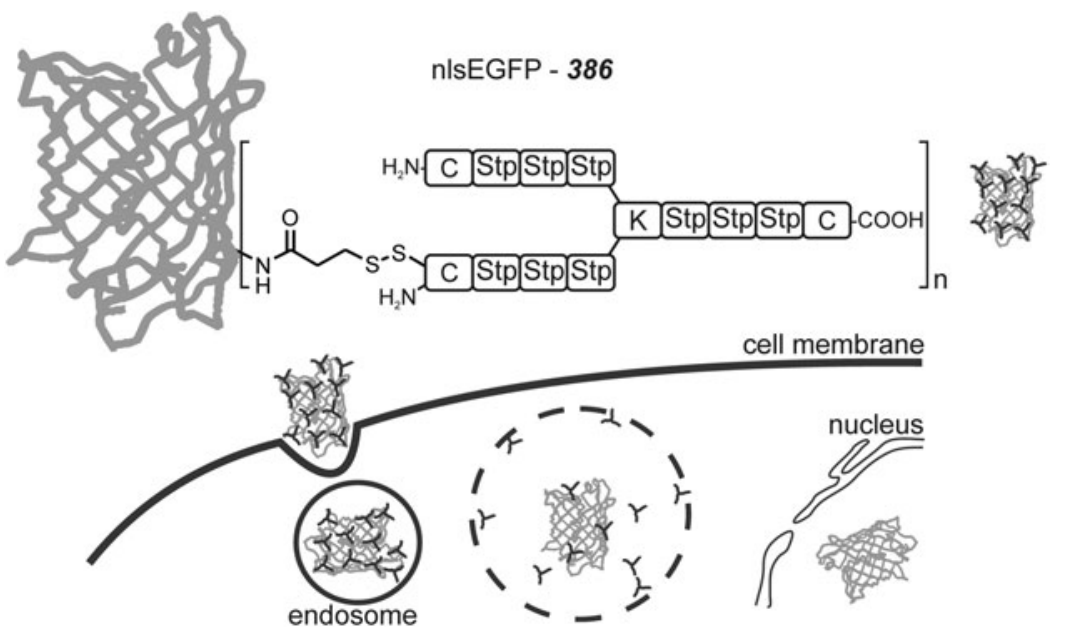

intravenous application $(9,60)$. The questions about the exact site of bioreduction might be less important for some nanocarrier designs but critical for others. The majority of the previously mentioned strategies build on cytosolic cleavage of multiple disulfide bonds of oligocationic carriers that had caged their cargo during the extracellular delivery. In those cases, it might be less important whether bioreduction of some fewer bonds starts at the cell surface, significantly takes place in the endosomal vesicle system, or largely happens in the cytosol. When cleavages of large numbers (approximately hundreds) of disulfide bonds per nanoparticles are required, the majority of cleavage processes can be assumed for the cytosolic location because of its larger reduction capacity.

Bioreducible disulfide linkages, however, have also been considered dynamic elements in earlier steps of the delivery process: For example, in the process of nanocarrier deshielding, which might be beneficial to occur at the cell surface or within endosomes, or for activation of endosomolytic domains within endosomal vesicles. The so-called "PEG dilemma" comprises the experiences that surface shielding of nanocarriers with PEG is very beneficial for extended blood circulation and (passive or active) tissue targeting, however, negatively affects intracellular uptake across endosomal membranes. Endosomal pH-sensitive cleavable PEGs are able to overcome this dilemma $(46,50,72,76,121)$. Thus, bioreductive cleavage of disulfide-bound PEG at the cell surface would be a very useful process $(8,54,82,107)$. In our own research, productive deshielding of PEGylated pDNA/PEI polyplexes was far more successful in utilizing $\mathrm{pH}$-labile bonded hydrazone (121) instead of disulfide-bonded (56) PEG chains.

Some approaches such as those reported by Lee and coworkers (90) successfully build on reductive liberation of endosomolytic agents within the endosome for subsequent cytosolic transport of the cargo. Such strategies are rationally supported by natural examples, including toxins and viral translocation that include a disulfide cleavage as a part of the translocation process $(69,78,83,86,99,112,120,123)$. For example, several toxins of the $\mathrm{AB}_{5}$ family (A toxic subunit, $\mathrm{B}$ receptor-binding carrier units), including cholera toxin, shiga toxin, or pertussis toxin, enter cells by endocytosis. This is followed by retrograde transport into the ER lumen, where repair chaperone PDIs recognize single disulfide bonds as "misfolded protein domains." Then, a physiological repair process named ER-associated degradation (ERAD) retrotranslocates the A unit through a pore to the cytosol for proteasome-mediated degradation (Fig. 8) (120). AB-type toxins such as ricin or Pseudomonas exotoxin, or some viruses such as SV40 (99), also contain disulfide linkages, which require cleavage for cytosolic translocation, presumably mediated by PDIs. For translocation, diphtheria toxin requires an analogous cleavage by PDI in the endosomal compartment (86). It, however, should be kept in mind that bioreductive potential in standard acidifying endosomes might be more limited (22) and applicable for special cases only.

In sum, many bioreductive approaches are built merely on educated guesses that are supported by facts from nature and empirical findings and imagination (hopefully not too far from reality). A more quantitative understanding of the bioreductive behavior of cellular processes, however, would provide enormous help for improved designs and, thus, present important opportunities for the future.

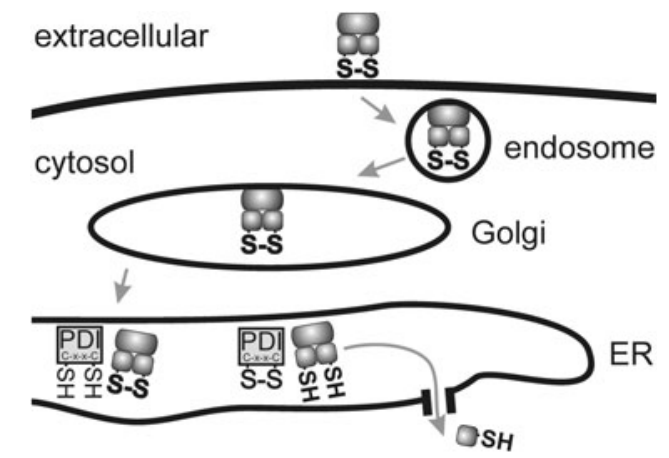

FIG. 8. Retrograde transport followed by reductive translocation to the cytosol. Several protein toxins (e.g. Cholera toxin, Shiga toxin, Pertussis toxin, ricin, or Pseudomonas exotoxin A) attach to receptors on the surface of the cell and are transported via Golgi to the Endoplasmic Reticulum (ER) by retrograde transport. A key disulfide is recognized as a "misfolded ER substrate" and reduced in the presence of a protein disulfide isomerase (PDI) followed by translocation of a toxin fragment to the cytosol. 
In this direction, Leroux and coworkers (5) developed a well-characterized, defined dendrimeric oligomer probe for analysis of bioreductive disulfide cleavage in cellular systems. The probe consists of generation 3 dendrimer PAMAM-G3 with disulfide-linked dye (BODIPY $)_{2}$, which provides the ability to distinguish between reduction of internal (dendrimer core) and surface disulfide bonds. Applying this system in four cell lines with different reductive potency (HeLa, A549> PC3 $>$ Caco- 2 cells), both interesting expected findings and surprising findings were made. For example, data based on pulsed thiol depletion and endocytosis inhibitor studies revealed the rather surprising finding that probe disulfide cleavage occurred exclusively at the extracellular cell surface, possibly triggered by cell surface oxidoreductases such as PDIs or chaperones (also belonging to the PDI family), with secreted thiols such as GSH acting as cofactors. Incubation with a cell membrane-impermeable oxidant completely suppressed bioreduction.

The same study evaluated bioreduction of the PAMAM probe after pDNA complex formation. Incorporation into such DNA polyplexes reduced the cell surface bioreduction, which is consistent with sterically restricted access of the probe to cell surface oxidoreductases. For the most reducing HeLa cell line, the logical distinction between cleavable disulfides in surface and core states became apparent. Moreover, the expected subsequent bioreduction after delivery into the acidic endosomal environment was incomplete. Intentionally, the authors had selected G3 PAMAM, which in contrast to higher-generation PAMAM or PEI does not have "proton sponge" based endosomal escape properties. The addition of chloroquine as an endosomolytic agent strongly enhanced bioreduction, which was consistent with endosomal escape and efficient reduction in the cytosol. As the authors note, "efficient bioreduction in the endosomes, while sometimes reported, is not a universal phenomenon and should be verified for each new system and its corresponding target cell line"' (5).

How may we utilize an increased knowledge about reductive characteristics of different biological microenvironments? Not only the biological surrounding influences the fate of disulfide bonds, but also the molecular chemical environment of disulfide bonds within a dynamic carrier can be tuned. For example, by stabilizing disulfide bonds by bulky groups providing sterical hindrance $(47,110)$, different exposure (core or surface) within a nanoparticle system (as illustrated in the PAMAM polymer example discussed earlier), the electrostatic environment facilitating or restricting electrostatic interaction with a reducing agent $(5,125)$, or the number and positioning of multiple disulfide bonds (126).

The influence of bulky groups on disulfide stability was shown in vitro with structures with methyl, benzene, and cationic residues localized next to disulfide bonds (110). When treated with $0.03 \mathrm{~m} M$ DTT at $\mathrm{pH} 7.4$, the stability was as follows: The most stable derivate was the one with methyl and benzene residue at the $\alpha$-C next to the disulfide bond, followed by the same derivate without methyl group, followed by a structure with an alkyl chain next to the disulfide group. The presence of a cationic charge in $\delta$-C position next to the disulfide resulted in a faster reduction than with all uncharged linkers mentioned earlier. Based on this information, the most stable and the most labile structure were incorporated in a linker to connect an antibody $(\mathrm{OX} 7)$ with a
Ricin A toxin subunit to form immunotoxins. These immunotoxins were tested in mice for stability in vivo. From the more stable disulfide-linked immunotoxin with methyl and benzene residue, $50 \%$ in active form and $50 \%$ in free antibody form were present in blood $48 \mathrm{~h}$ after an intravenous injection. In contrast, the bioreducible linkage with the cationic element in its environment reached the same cleavage stage (50/50 ratio immunotoxin/free antibody) after only $8 \mathrm{~h}$ (110). More recently (47), a systematic study of disulfidelinked antibody-maytansinoid immunotoxins was reported while evaluating the disulfide-linker stability and antitumoral activity in vivo in mice. Sterical hindrance (by methyl group substitutions flanking the disulfide bonds) enhanced stability to reductive cleavage by DTT and plasma stability in mice. In in vivo efficacy testing, a conjugate with intermediate disulfide bond stability (having two methyl groups on the maytansinoid side of the disulfide linkage but no methyl substitution on the antibody linker side) displayed the highest antitumoral efficacy.

Not only the sterical and electrostatic environment of disulfides, but also the reducing agents and the $\mathrm{pH}$ have a crucial influence on the stability of a disulfide bond. It has been shown that positively charged amino acids next to a cysteine in a peptide destabilized the disulfide bond between oxidized dimers in a $10 \mathrm{~m} M$ GSH solution at $\mathrm{pH} 4.9$ (mimics late endosomal/lysosomal environment) (125) The influence was higher for amino acids with higher $\mathrm{pKa}$ values (highest for arginine with $\mathrm{pKa} 12.1)$ and if more positively charged amino acids were incorporated. The distance $(\alpha$ - or $\beta$ - amino acid next to cysteine) played a minor role. Analogous negatively charged amino acids with low pKa values (glutamic acid with $\mathrm{pKa} 4.3$ has the strongest influence) stabilized the disulfide bond. Consequently, the half life of structures with $\alpha$ - and $\beta$-arginine was only $0.17 \mathrm{~h}$ compared with $8.7 \mathrm{~h}$ for structures with $\alpha$ - and $\beta$-glutamic acid. If GSH, which is also present in its deprotonated GS--form, was exchanged by cysteine as a reducing agent, which also can be deprotonated, the same tendency could be observed. If cysteamine, which does not have a negatively charged form, was used, the half life for all tested peptides was comparable. For higher $\mathrm{pH}$ values, such as $\mathrm{pH} 7.4$ in the cytosol, the cleavage kinetics in GSH redox buffer accelerated profoundly (from $8.7 \mathrm{~h}$ for $\mathrm{pH}$ 4.9 to $0.1 \mathrm{~h}$ in half life for the structure with $\alpha$-and $\beta$-glutamic acid). The higher amounts of charged $\mathrm{GS}^{-}$at higher $\mathrm{pH}$ seem to be responsible for this faster cleavage. Special formations of cysteines embedded in a peptidic environment can influence not only the kinetics but also the formation of disulfides in structures. A motif consisting of cysteine-any amino acid-cysteine (C-X-C) was evaluated for different flanking and central natural amino acids and revealed the best properties for the cationic amino acid arginine combined with the flanking amino acids glutamic acid (G-C-R-C-G) (126). The motif not only offered a prolonged resistance against a reducing solution with $0.02 \mathrm{~m} M \mathrm{GSH}$ redox buffer (more than $60 \%$ remaining, compared with less than $10 \%$ for single cysteines after $6 \mathrm{~h}$ ), but also formed orthogonal twin disulfide dimers in the presence of single cysteines selectively. The arginine was shown to strongly direct the equilibrium toward the twin disulfide dimers. Responsibility for this effect seems to be the positive charge that promotes the reactivity of thiolates, which are intermediately required to form a disulfide bond. The surrounding glutamic acids seem to stabilize 
the disulfide bond by reducing the rates of disulfides exchange in GSH redox buffer.

\section{Conclusions}

The bioreducible structure of disulfide bonds offers some most beneficial options to oligocationic carriers for gene and protein delivery. Importantly, it provides a straightforward option for the design of dynamic carriers and shuttles discriminating between intracellular and extracellular cytosolic locations. The stability of the cargo polyplex that is needed during the harsh extracellular conditions and during cellular uptake can be provided by cross-links in a two- or threedimensional manner via covalent conjugation or caging of the cargo. While pDNA polyplexes can be built on purely electrostatic interactions with commonly HMW carriers, the smaller siRNAs and cargo proteins may critically depend on such disulfide stabilizations. Intracellularly, disulfide bonds are efficiently cleaved by the reductive environment, releasing the cargo in a functional form undisturbed from the delivery shuttle. As an additional benefit, bioreduction disassembles oligocationic carriers into smaller, usually nontoxic fragments. Chemical tuning of bioreductive elements for site-/time-specific cleavage presents an encouraging future option for activating delivery functions beyond simple assembly/disassembly, for example, triggered deshielding or unmasking of endosomolytic, cytosolic transport and cargo release elements.

\section{Acknowledgments}

The authors thank Olga Brück (LMU) for skillful assistance in preparing this article. This work was supported by the German Research Foundation (DFG) special research focus project grant SFB1032 B4 and the Cluster of Excellence Nanosystems Initiative Munich (NIM).

\section{References}

1. Behr JP. The proton sponge: a trick to enter cells the viruses did not exploit. Chimia 51: 34-36, 1997.

2. Benjaminsen RV, Mattebjerg MA, Henriksen JR, Moghimi SM, and Andresen TL. The possible "proton sponge" effect of polyethylenimine (PEI) does not include change in lysosomal pH. Mol Ther 21: 149-157, 2013.

3. Boussif O, Lezoualc'h F, Zanta MA, Mergny MD, Scherman D, Demeneix B, and Behr JP. A versatile vector for gene and oligonucleotide transfer into cells in culture and in vivo: polyethylenimine. Proc Natl Acad Sci USA 92: 7297-7301, 1995.

4. Breunig M, Lungwitz U, Liebl R, and Goepferich A. Breaking up the correlation between efficacy and toxicity for nonviral gene delivery. Proc Natl Acad Sci USA 104: 14454-14459, 2007.

5. Brulisauer L, Kathriner N, Prenrecaj M, Gauthier MA, and Leroux JC. Tracking the bioreduction of disulfide-containing cationic dendrimers. Angew Chem Int Ed Engl 51: 12454-12458, 2012.

6. Bumcrot D, Manoharan M, Koteliansky V, and Sah DW. RNAi therapeutics: a potential new class of pharmaceutical drugs. Nat Chem Biol 2: 711-719, 2006.

7. Burke RS and Pun SH. Extracellular barriers to in vivo PEI and PEGylated PEI polyplex-mediated gene delivery to the liver. Bioconjug Chem 19: 693-704, 2008.
8. Cerritelli S, Velluto D, and Hubbell JA. PEG-SS-PPS: reduction-sensitive disulfide block copolymer vesicles for intracellular drug delivery. Biomacromolecules 8: 19661972, 2007.

9. Chen X, Bai Y, Zaro JL, and Shen WC. Design of an in vivo cleavable disulfide linker in recombinant fusion proteins. Biotechniques 49: 513-518, 2010.

10. Chen X, Dudgeon N, Shen L, and Wang JH. Chemical modification of gene silencing oligonucleotides for drug discovery and development. Drug Discov Today 10: 587593, 2005.

11. Choi $\mathrm{S}$ and Lee KD. Enhanced gene delivery using disulfide-crosslinked low molecular weight polyethylenimine with listeriolysin o-polyethylenimine disulfide conjugate. J Control Release 131: 70-76, 2008.

12. Christensen LV, Chang CW, Kim WJ, Kim SW, Zhong Z, Lin C, Engbersen JF, and Feijen J. Reducible poly(amido ethylenimine)s designed for triggered intracellular gene delivery. Bioconjug Chem 17: 1233-1240, 2006.

13. Dalkara D, Chandrashekhar C, and Zuber G. Intracellular protein delivery with a dimerizable amphiphile for improved complex stability and prolonged protein release in the cytoplasm of adherent cell lines. J Control Release 116: 353-359, 2006.

14. Debs RJ, Freedman LP, Edmunds S, Gaensler KL, Duzgunes N, and Yamamoto KR. Regulation of gene-expression invivo by liposome-mediated delivery of a purified transcription factor. J Biol Chem 265: 10189-10192, 1990.

15. DeLeve LD and Kaplowitz N. Glutathione metabolism and its role in hepatotoxicity. Pharmacol Ther 52: 287305, 1991.

16. DeRouchey J, Schmidt C, Walker GF, Koch C, Plank C, Wagner E, and Rädler JO. Monomolecular assembly of siRNA and Poly(ethylene glycol)-peptide copolymers. Biomacromolecules 9: 724-732, 2008.

17. Didenko VV, Ngo H, and Baskin DS. Polyethyleneimine as a transmembrane carrier of fluorescently labeled proteins and antibodies. Anal Biochem 344: 168-173, 2005.

18. Dohmen C, Edinger D, Frohlich T, Schreiner L, Lachelt U, Troiber C, Radler J, Hadwiger P, Vornlocher HP, and Wagner E. Nanosized multifunctional polyplexes for receptor-mediated SiRNA delivery. ACS Nano 6: 51985208, 2012.

19. Dohmen C, Frohlich T, Lachelt U, Rohl I, Vornlocher H-P, Hadwiger P, and Wagner E. Defined Folate-PEGsiRNA conjugates for receptor-specific gene silencing. Mol Ther Nucleic Acids 1: e7, 2012.

20. Elbashir SM, Harborth J, Lendeckel W, Yalcin A, Weber $\mathrm{K}$, and Tuschl T. Duplexes of 21-nucleotide RNAs mediate RNA interference in cultured mammalian cells. Nature 411: 494-498, 2001.

21. Fass D. Disulfide bonding in protein biophysics. Аппи Rev Biophys 41: 63-79, 2012.

22. Feener EP, Shen WC, and Ryser HJ. Cleavage of disulfide bonds in endocytosed macromolecules. A processing not associated with lysosomes or endosomes. J Biol Chem 265: 18780-18785, 1990.

23. Felgner PL, Barenholz Y, Behr JP, Cheng SH, Cullis P, Huang L, Jessee JA, Seymour L, Szoka F, Thierry AR, Wagner E, and $\mathrm{Wu}$ G. Nomenclature for synthetic gene delivery systems. Hum Gene Ther 8: 511-512, 1997.

24. Fidias P, Grossbard M, and Lynch TJ, Jr. A phase II study of the immunotoxin N901-blocked ricin in small-cell lung cancer. Clin Lung Cancer 3: 219-222, 2002. 
25. Filpula D, Yang K, Basu A, Hassan R, Xiang L, Zhang Z, Wang M, Wang QC, Ho M, Beers R, Zhao H, Peng P, Zhou J, Li X, Petti G, Janjua A, Liu J, Wu D, Yu D, Longley C, FitzGerald D, Kreitman RJ, and Pastan I. Releasable PEGylation of mesothelin targeted immunotoxin SS1P achieves single dosage complete regression of a human carcinoma in mice. Bioconjug Chem 18: 773-784, 2007.

26. Forrest ML, Koerber JT, and Pack DW. A degradable polyethylenimine derivative with low toxicity for highly efficient gene delivery. Bioconjug Chem 14: 934-940, 2003.

27. Frankel $\mathrm{AD}$ and Pabo CO. Cellular uptake of the tat protein from human immunodeficiency virus. Cell 55: 1189-1193, 1988.

28. Fröhlich T, Edinger D, Kläger R, Troiber C, Salcher E, Badgujar N, Martin I, Schaffert D, Cengizeroglu A, Hadwiger P, Vornlocher H-P, and Wagner E. Structureactivity relationships of siRNA carriers based on sequencedefined oligo (ethane amino) amides. J Control Release 160: 532-541, 2012.

29. Frohlich T, Edinger D, Russ V, and Wagner E. Stabilization of polyplexes via polymer crosslinking for efficient siRNA delivery. Eur J Pharm Sci 47: 914-920, 2012.

30. Futami J, Kitazoe M, Maeda T, Nukui E, Sakaguchi M, Kosaka J, Miyazaki M, Kosaka M, Tada H, Seno M, Sasaki J, Huh NH, Namba M, and Yamada H. Intracellular delivery of proteins into mammalian living cells by polyethylenimine-cationization. J Biosci Bioeng 99: 95103, 2005.

31. Gosselin MA, Guo W, and Lee RJ. Efficient gene transfer using reversibly cross-linked low molecular weight polyethylenimine. Bioconjug Chem 12: 989-994, 2001.

32. Grandinetti G, Ingle NP, and Reineke TM. Interaction of poly(ethylenimine)-DNA polyplexes with mitochondria: implications for a mechanism of cytotoxicity. Mol Pharm 8: 1709-1719, 2011.

33. Green M and Loewenstein PM. Autonomous functional domains of chemically synthesized human immunodeficiency virus tat trans-activator protein. Cell 55: 11791188, 1988.

34. Han S, Mahato RI, Sung YK, and Kim SW. Development of biomaterials for gene therapy. Mol Ther 2: 302-317, 2000.

35. Hartmann L. Polymers for Control Freaks: SequenceDefined Poly(amidoamine)s and Their Biomedical Applications. Macromol Chem Phys 212: 8-13, 2011.

36. Hartmann L, Hafele S, Peschka-Suss R, Antonietti M, and Borner HG. Tailor-made Poly(amidoamine)s for controlled complexation and condensation of DNA. Chemistry 14: 2025-2033, 2008.

37. Hartmann L, Häfele S, Peschka-Süss R, Antonietti M, and Börner HG. Sequence positioning of disulfide linkages to program the degradation of monodisperse Poly(amidoamines). Macromolecules 40: 7771-7776, 2007.

38. Hartmann L, Krause E, Antonietti M, and Borner HG. Solid-phase supported polymer synthesis of sequencedefined, multifunctional poly(amidoamines). Biomacromolecules 7: 1239-1244, 2006.

39. Holmgren A and Bjornstedt M. Thioredoxin and thioredoxin reductase. Methods Enzymol 252: 199-208, 1995.

40. Ibrahim AF, Weirauch U, Thomas M, Grunweller A, Hartmann RK, and Aigner A. MicroRNA replacement therapy for miR-145 and miR-33a is efficacious in a model of colon carcinoma. Cancer Res 71: 5214-5224, 2011.

41. Itaka K, Harada A, Yamasaki Y, Nakamura K, Kawaguchi $\mathrm{H}$, and Kataoka K. In situ single cell observation by fluorescence resonance energy transfer reveals fast intracytoplasmic delivery and easy release of plasmid DNA complexed with linear polyethylenimine. J Gene Med 6: 76-84, 2004.

42. Joliot A, Pernelle C, Deagostini-Bazin H, and Prochiantz A. Antennapedia homeobox peptide regulates neural morphogenesis. Proc Natl Acad Sci USA 88: 1864-1868, 1991.

43. Jones DP, Carlson JL, Samiec PS, Sternberg P, Jr., Mody VC, Jr., Reed RL, and Brown LA. Glutathione measurement in human plasma. Evaluation of sample collection, storage and derivatization conditions for analysis of dansyl derivatives by HPLC. Clin Chim Acta 275: 175-184, 1998.

44. Joshua-Tor L. siRNAs at RISC. Structure 12: 1120-1122, 2004.

45. June RK, Gogoi K, Eguchi A, Cui XS, and Dowdy SF. Synthesis of a $\mathrm{pH}$-sensitive nitrilotriacetic linker to peptide transduction domains to enable intracellular delivery of histidine imidazole ring-containing macromolecules. $J$ Am Chem Soc 132: 10680-10682, 2010.

46. Kale AA and Torchilin VP. "Smart" drug carriers: PEGylated TATp-modified pH-sensitive liposomes. J Liposome Res 17: 197-203, 2007.

47. Kellogg BA, Garrett L, Kovtun Y, Lai KC, Leece B, Miller M, Payne G, Steeves R, Whiteman KR, Widdison W, Xie H, Singh R, Chari RV, Lambert JM, and Lutz RJ. Disulfide-linked antibody-maytansinoid conjugates: optimization of in vivo activity by varying the steric hindrance at carbon atoms adjacent to the disulfide linkage. Bioconjug Chem 22: 717-727, 2011.

48. Kim TI and Kim SW. Bioreducible polymers for gene delivery. Reactive Funct Polym 71: 344-349, 2011.

49. Kloeckner J, Bruzzano S, Ogris M, and Wagner E. Gene carriers based on hexanediol diacrylate linked oligoethylenimine: effect of chemical structure of polymer on biological properties. Bioconjug Chem 17: 1339-1345, 2006.

50. Knorr V, Allmendinger L, Walker GF, Paintner FF, and Wagner E. An acetal-based PEGylation reagent for $\mathrm{pH}-$ sensitive shielding of DNA polyplexes. Bioconjug Chem 18: 1218-1225, 2007.

51. Knorr V, Ogris M, and Wagner E. An acid sensitive ketalbased polyethylene glycol-oligoethylenimine copolymer mediates improved transfection efficiency at reduced toxicity. Pharm Res 25: 2937-2945, 2008.

52. Koo H, Jin GW, Kang H, Lee Y, Nam K, Zhe Bai C, and Park JS. Biodegradable branched poly(ethylenimine sulfide) for gene delivery. Biomaterials 31: 988-997, 2010.

53. Kota J, Chivukula RR, O'Donnell KA, Wentzel EA, Montgomery CL, Hwang HW, Chang TC, Vivekanandan P, Torbenson M, Clark KR, Mendell JR, and Mendell JT. Therapeutic microRNA delivery suppresses tumorigenesis in a murine liver cancer model. Cell 137: 1005-1017, 2009.

54. Kuai R, Yuan W, Qin Y, Chen H, Tang J, Yuan M, Zhang $\mathrm{Z}$, and He Q. Efficient delivery of payload into tumor cells in a controlled manner by TAT and thiolytic cleavable PEG co-modified liposomes. Mol Pharm 7: 1816-1826, 2010. 
55. Kukowska-Latallo JF, Bielinska AU, Johnson J, Spindler $\mathrm{R}$, Tomalia DA, and Baker JR, Jr. Efficient transfer of genetic material into mammalian cells using Starburst polyamidoamine dendrimers. Proc Natl Acad Sci USA 93: 4897-4902, 1996.

56. Kursa M, Walker GF, Roessler V, Ogris M, Roedl W, Kircheis R, and Wagner E. Novel shielded transferrinpolyethylene glycol-polyethylenimine/DNA complexes for systemic tumor-targeted gene transfer. Bioconjug Chem 14: 222-231, 2003.

57. Kwok A and Hart SL. Comparative structural and functional studies of nanoparticle formulations for DNA and siRNA delivery. Nanomedicine 7: 210-219, 2011.

58. Lee SY, Huh MS, Lee S, Lee SJ, Chung H, Park JH, Oh YK, Choi K, Kim K, and Kwon IC. Stability and cellular uptake of polymerized siRNA (poly-siRNA)/polyethylenimine (PEI) complexes for efficient gene silencing. J Control Release 141: 339-346, 2010.

59. Lee Y, Ishii T, Kim HJ, Nishiyama N, Hayakawa Y, Itaka K, and Kataoka K. Efficient delivery of bioactive antibodies into the cytoplasm of living cells by chargeconversional polyion complex micelles. Angew Chem Int Ed Engl 49: 2552-2555, 2010.

60. Letvin NL, Goldmacher VS, Ritz J, Yetz JM, Schlossman $\mathrm{SF}$, and Lambert JM. In vivo administration of lymphocytespecific monoclonal antibodies in nonhuman primates. In vivo stability of disulfide-linked immunotoxin conjugates. J Clin Invest 77: 977-984, 1986.

61. Lew D, Parker SE, Latimer T, Abai AM, KuwaharaRundell A, Doh SG, Yang Z-Y, Laface D, Gromkowski SH, Nabel GJ, Manthorpe M, and Norman J. Cancer Gene Therapy Using Plasmid DNA: Pharmacokinetic Study of DNA Following Injection in Mice. Hum Gene Ther 6: 553-564, 1995.

62. Liguori L, Marques B, Villegas-Mendez A, Rothe R, and Lenormand JL. Liposomes-mediated delivery of proapoptotic therapeutic membrane proteins. $J$ Control Release 126: 217-227, 2008.

63. Lin C, Blaauboer C-J, Timoneda MM, Lok MC, van Steenbergen M, Hennink WE, Zhong Z, Feijen J, and Engbersen JFJ. Bioreducible poly(amido amine)s with oligoamine side chains: synthesis, characterization, and structural effects on gene delivery. J Control Release 126: 166-174, 2008.

64. Lin C, Zhong Z, Lok MC, Jiang X, Hennink WE, Feijen J, and Engbersen JF. Novel bioreducible poly(amido amine)s for highly efficient gene delivery. Bioconjug Chem 18: 138-145, 2007.

65. Maier K, Martin I, and Wagner E. Sequence defined disulfide-linked shuttle for strongly enhanced intracellular protein delivery. Mol Pharm 9: 3560-3568, 2012.

66. Maier K and Wagner E. Acid-labile traceless click linker for protein transduction. J Am Chem Soc 134: 1016910173, 2012.

67. Matsumoto S, Christie RJ, Nishiyama N, Miyata K, Ishii A, Oba M, Koyama H, Yamasaki Y, and Kataoka K. Environment-responsive block copolymer micelles with a disulfide cross-linked core for enhanced siRNA delivery. Biomacromolecules 10: 119-127, 2009.

68. McKenzie DL, Kwok KY, and Rice KG. A potent new class of reductively activated peptide gene delivery agents. J Biol Chem 275: 9970-9977, 2000.

69. Mercer J, Schelhaas M, and Helenius A. Virus entry by endocytosis. Annu Rev Biochem 79: 803-833, 2010.
70. Meyer M, Dohmen C, Philipp A, Kiener D, Maiwald G, Scheu C, Ogris M, and Wagner E. Synthesis and biological evaluation of a bioresponsive and endosomolytic siRNA-polymer conjugate. Mol Pharm 6: 752-762, 2009.

71. Meyer M, Philipp A, Oskuee R, Schmidt C, and Wagner E. Breathing life into polycations: functionalization with $\mathrm{pH}$-responsive endosomolytic peptides and polyethylene glycol enables siRNA delivery. J Am Chem Soc 130: 3272-3273, 2008.

72. Meyer $\mathrm{M}$ and Wagner E. pH-responsive shielding of nonviral gene vectors. Expert Opin Drug Deliv 3: 563-571, 2006.

73. Midoux $\mathrm{P}$ and Monsigny $\mathrm{M}$. Efficient gene transfer by histidylated polylysine/pDNA complexes. Bioconjug Chem 10: 406-411, 1999.

74. Moghimi SM, Symonds P, Murray JC, Hunter AC, Debska G, and Szewczyk A. A two-stage poly(ethylenimine)mediated cytotoxicity: implications for gene transfer/ therapy. Mol Ther 11: 990-995, 2005.

75. Mok H, Lee SH, Park JW, and Park TG. Multimeric small interfering ribonucleic acid for highly efficient sequencespecific gene silencing. Nat Mater 9: 272-278, 2010.

76. Nie Y, Günther M, Gu Z, and Wagner E. Pyridylhydrazonebased PEGylation for $\mathrm{pH}$-reversible lipopolyplex shielding. Biomaterials 32: 858-869, 2011.

77. Noiva R. Protein disulfide isomerase: the multifunctional redox chaperone of the endoplasmic reticulum. Semin Cell Dev Biol 10: 481-493, 1999.

78. Oh KJ, Senzel L, Collier RJ, and Finkelstein A. Translocation of the catalytic domain of diphtheria toxin across planar phospholipid bilayers by its own T domain. Proc Natl Acad Sci USA 96: 8467-8470, 1999.

79. Pack DW, Hoffman AS, Pun S, and Stayton PS. Design and development of polymers for gene delivery. Nat Rev Drug Discov 4: 581-593, 2005.

80. Parmar RG, Busuek M, Walsh ES, Leander KR, Howell BJ, Sepp-Lorenzino L, Kemp E, Crocker LS, Leone A, Kochansky CJ, Carr BA, Garbaccio RM, Colletti SL, and Wang W. Endosomolytic bioreducible Poly(amido amine disulfide) polymer conjugates for the in vivo systemic delivery of siRNA therapeutics. Bioconjug Chem 24: 640 647, 2013.

81. Pichon C, Roufai MB, Monsigny M, and Midoux P. Histidylated oligolysines increase the transmembrane passage and the biological activity of antisense oligonucleotides. Nucleic Acids Res 28: 504-512, 2000.

82. Ping Y, Hu Q, Tang G, and Li J. FGFR-targeted gene delivery mediated by supramolecular assembly between beta-cyclodextrin-crosslinked PEI and redox-sensitive PEG. Biomaterials 34: 6482-6494, 2013.

83. Pirazzini M, Bordin F, Rossetto O, Shone CC, Binz T, and Montecucco C. The thioredoxin reductase-thioredoxin system is involved in the entry of tetanus and botulinum neurotoxins in the cytosol of nerve terminals. FEBS Lett 587: 150-155, 2013.

84. Plank C, Mechtler K, Szoka FC, Jr., and Wagner E. Activation of the complement system by synthetic DNA complexes: a potential barrier for intravenous gene delivery. Hum Gene Ther 7: 1437-1446, 1996.

85. Prochiantz A. Messenger proteins: homeoproteins, TAT and others. Curr Opin Cell Biol 12: 400-406, 2000.

86. Ratts R, Zeng H, Berg EA, Blue C, McComb ME, Costello CE, vanderSpek JC, and Murphy JR. The cytosolic entry of diphtheria toxin catalytic domain requires a host 
cell cytosolic translocation factor complex. J Cell Biol 160: 1139-1150, 2003.

87. Read ML, Bremner KH, Oupický D, Green NK, Searle $\mathrm{PF}$, and Seymour LW. Vectors based on reducible polycations facilitate intracellular release of nucleic acids. $J$ Gene Med 5: 232-245, 2003.

88. Read ML, Singh S, Ahmed Z, Stevenson M, Briggs SS, Oupicky D, Barrett LB, Spice R, Kendall M, Berry M, Preece JA, Logan A, and Seymour LW. A versatile reducible polycation-based system for efficient delivery of a broad range of nucleic acids. Nucleic Acids Res 33: e86, 2005.

89. Russ V, Elfberg H, Thoma C, Kloeckner J, Ogris M, and Wagner E. Novel degradable oligoethylenimine acrylate ester-based pseudodendrimers for in vitro and in vivo gene transfer. Gene Ther 15: 18-29, 2008.

90. Saito G, Amidon GL, and Lee KD. Enhanced cytosolic delivery of plasmid DNA by a sulfhydryl-activatable listeriolysin $\mathrm{O}$ /protamine conjugate utilizing cellular reducing potential. Gene Ther 10: 72-83, 2003.

91. Saito G, Swanson JA, and Lee KD. Drug delivery strategy utilizing conjugation via reversible disulfide linkages: role and site of cellular reducing activities. Adv Drug Deliv Rev 55: 199-215, 2003.

92. Salcher EE, Kos P, Frohlich T, Badgujar N, Scheible M, and Wagner E. Sequence-defined four-arm oligo(ethanamino)amides for pDNA and siRNA delivery: Impact of building blocks on efficacy. $J$ Control Release 164: 380-386, 2012.

93. Sawant R and Torchilin V. Intracellular transduction using cell-penetrating peptides. Mol Biosyst 6: 628-640, 2010.

94. Schafer FQ and Buettner GR. Redox environment of the cell as viewed through the redox state of the glutathione disulfide/glutathione couple. Free Radic Biol Med 30: 1191-1212, 2001.

95. Schaffer DV, Fidelman NA, Dan N, and Lauffenburger DA. Vector unpacking as a potential barrier for receptormediated polyplex gene delivery. Biotechnol Bioeng 67: 598-606, 2000.

96. Schaffert D, Badgujar N, and Wagner E. Novel Fmocpolyamino acids for solid-phase synthesis of defined polyamidoamines. Org Lett 13: 1586-1589, 2011.

97. Schaffert D, Troiber C, Salcher EE, Frohlich T, Martin I, Badgujar N, Dohmen C, Edinger D, Klager R, Maiwald G, Farkasova K, Seeber S, Jahn-Hofmann K, Hadwiger P, and Wagner E. Solid-phase synthesis of sequence-defined T-, i-, and U-shape polymers for pDNA and siRNA delivery. Angew Chem Int Ed Engl 50: 8986-8989, 2011.

98. Schaffert D, Troiber C, and Wagner E. New sequencedefined polyaminoamides with tailored endosomolytic properties for plasmid DNA delivery. Bioconjug Chem 23: 1157-1165, 2012.

99. Schelhaas M, Malmstrom J, Pelkmans L, Haugstetter J, Ellgaard L, Grunewald K, and Helenius A. Simian Virus 40 depends on ER protein folding and quality control factors for entry into host cells. Cell 131: 516-529, 2007.

100. Schlossbauer A, Dohmen C, Schaffert D, Wagner E, and Bein T. pH-responsive release of acetal-linked melittin from SBA-15 mesoporous silica. Angew Chem Int Ed Engl 50: 6828-6830, 2011.

101. Schnell R, Borchmann P, Staak JO, Schindler J, Ghetie V, Vitetta ES, and Engert A. Clinical evaluation of ricin Achain immunotoxins in patients with Hodgkin's lymphoma. Ann Oncol 14: 729-736, 2003.
102. Scholz C and Wagner E. Therapeutic plasmid DNA versus siRNA delivery: Common and different tasks for synthetic carriers. J Control Release 161: 554-565, 2012.

103. Schwarze SR, Ho A, Vocero-Akbani A, and Dowdy SF. In vivo protein transduction: delivery of a biologically active protein into the mouse. Science 285: 1569-1572, 1999.

104. Son S, Namgung R, Kim J, Singha K, and Kim WJ. Bioreducible polymers for gene silencing and delivery. Acc Chem Res 45: 1100-1112, 2012.

105. Sonawane ND, Szoka FC, Jr., and Verkman AS. Chloride Accumulation and Swelling in Endosomes Enhances DNA Transfer by Polyamine-DNA Polyplexes. J Biol Chem 278: 44826-44831, 2003.

106. Stolnik S and Shakesheff K. Formulations for delivery of therapeutic proteins. Biotechnol Lett 31: 1-11, 2009.

107. Sun H, Guo B, Cheng R, Meng F, Liu H, and Zhong Z. Biodegradable micelles with sheddable poly(ethylene glycol) shells for triggered intracellular release of doxorubicin. Biomaterials 30: 6358-6366, 2009.

108. Tanna AP, Budenz DL, Bandi J, Feuer WJ, Feldman RM, Herndon LW, Rhee DJ, Whiteside-de Vos J, Huang J, and Anderson DR. Glaucoma Progression Analysis software compared with expert consensus opinion in the detection of visual field progression in glaucoma. Ophthalmology 119: 468-473, 2012.

109. Thomas M, Ge Q, Lu JJ, Chen J, and Klibanov AM. Cross-linked small polyethylenimines: while still nontoxic, deliver DNA efficiently to mammalian cells in vitro and in vivo. Pharm Res 22: 373-380, 2005.

110. Thorpe PE, Wallace PM, Knowles PP, Relf MG, Brown AN, Watson GJ, Knyba RE, Wawrzynczak EJ, and Blakey DC. New coupling agents for the synthesis of immunotoxins containing a hindered disulfide bond with improved stability in vivo. Cancer Res 47: 5924-5931, 1987.

111. Troiber C, Kasper JC, Milani S, Scheible M, Martin I, Schaubhut F, Kuchler S, Radler J, Simmel FC, Friess W, and Wagner E. Comparison of four different particle sizing methods for siRNA polyplex characterization. Eur J Pharm Biopharm 84: 255-264, 2012.

112. Tsai B, Rodighiero C, Lencer WI, and Rapoport TA. Protein disulfide isomerase acts as a redox-dependent chaperone to unfold cholera toxin. Cell 104: 937-948, 2001.

113. Tuschl T. RNA interference and small interfering RNAs. Chembiochem 2: 239-245, 2001.

114. Vincenzi B, Zoccoli A, Pantano F, Venditti O, and Galluzzo S. CETUXIMAB: From Bench to Bedside. Curr Cancer Drug Targets 10: 80-95, 2010.

115. von Harpe A, Petersen H, Li Y, and Kissel T. Characterization of commercially available and synthesized polyethylenimines for gene delivery. $J$ Control Release 69: 309-322, 2000.

116. Wagner E. Programmed drug delivery: nanosystems for tumor targeting. Expert Opin Biol Ther 7: 587-593, 2007.

117. Wagner E. Polymers for siRNA Delivery: Inspired by Viruses to be Targeted, Dynamic, and Precise. Acc Chem Res 45: 1005-1013, 2012.

118. Wagner E. Biomaterials in RNAi therapeutics: quo vadis? Biomater Sci 1: 804-809, 2013.

119. Wagner E and Kloeckner J. Gene delivery using polymer therapeutics. Adv Polym Sci 192: 135-173, 2006.

120. Walczak CP, Bernardi KM, and Tsai B. Endoplasmic reticulum-dependent redox reactions control endoplasmic 
reticulum-associated degradation and pathogen entry. Antioxid Redox Signal 16: 809-818, 2012.

121. Walker GF, Fella C, Pelisek J, Fahrmeir J, Boeckle S, Ogris $\mathrm{M}$, and Wagner E. Toward synthetic viruses: endosomal pH-triggered deshielding of targeted polyplexes greatly enhances gene transfer in vitro and in vivo. Mol Ther 11: 418-425, 2005.

122. Wang X-L, Xu R, and Lu Z-R. A peptide-targeted delivery system with $\mathrm{pH}$-sensitive amphiphilic cell membrane disruption for efficient receptor-mediated siRNA delivery. J Control Release 134: 207-213, 2009.

123. Wernick NL, Chinnapen DJ, Cho JA, and Lencer WI. Cholera toxin: an intracellular journey into the cytosol by way of the endoplasmic reticulum. Toxins (Basel) 2: 310325, 2010.

124. Wolfert MA and Seymour LW. Atomic force microscopic analysis of the influence of the molecular weight of poly(L)lysine on the size of polyelectrolyte complexes formed with DNA 723. Gene Ther 3: 269-273, 1996.

125. Wu C, Belenda C, Leroux JC, and Gauthier MA. Interplay of chemical microenvironment and redox environment on thiol-disulfide exchange kinetics. Chemistry 17: 1006410070, 2011.

126. Wu C, Leroux JC, and Gauthier MA. Twin disulfides for orthogonal disulfide pairing and the directed folding of multicyclic peptides. Nat Chem 4: 1044-1049, 2012.

127. Xia CQ, Wang J, and Shen WC. Hypoglycemic effect of insulin-transferrin conjugate in streptozotocin-induced diabetic rats. J Pharmacol Exp Ther 295: 594-600, 2000.

128. Zhang G, Liu J, Yang Q, Zhuo R, and Jiang X. Disulfidecontaining brushed polyethylenimine derivative synthesized by click chemistry for nonviral gene delivery. Bioconjug Chem, 23: 1290-1299, 2012.

129. Ziady AG, Ferkol T, Dawson DV, Perlmutter DH, and Davis PB. Chain length of the polylysine in receptortargeted gene transfer complexes affects duration of reporter gene expression both in vitro and in vivo. $J$ Biol Chem 274: 4908-4916, 1999.

130. Zinselmeyer BH, Mackay SP, Schatzlein AG, and Uchegbu IF. The lower-generation polypropylenimine dendrimers are effective gene-transfer agents. Pharm Res 19: 960-967, 2002.

131. Zou SM, Erbacher P, Remy JS, and Behr JP. Systemic linear polyethylenimine (L-PEI)-mediated gene delivery in the mouse. J Gene Med 2: 128-134, 2000.

Address correspondence to: Prof. Ernst Wagner Pharmaceutical Biotechnology Center for System-Based Drug Research Ludwig-Maximilians-University Butenandtstrasse 5-13 Munich D-81377

Germany

E-mail: ernst.wagner@cup.uni-muenchen.de

Date of first submission to ARS Central, October 24, 2013; date of acceptance, November 12, 2013.

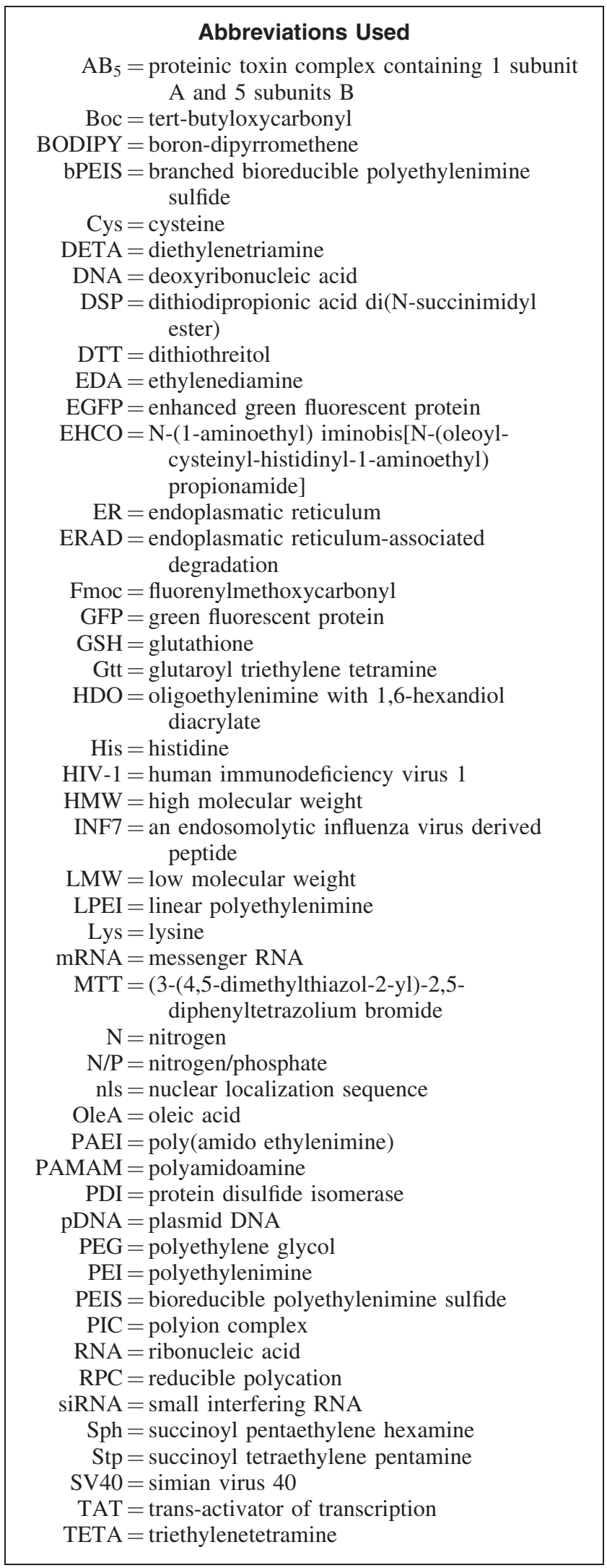

